\title{
Assessment Research of Bijie Drought Risk Based On Cloud Model
}

\author{
Ying He \\ School of Finance, Guizhou University of Finance \& Ecnomics, Guiyang 400020, China \\ *E-mail: obying@163.com \\ Received 20 November 2013 \\ Accepted 13 December 2013 \\ Abstract
}

\begin{abstract}
This paper chooses 8 cities and counties of Bijie area as the research target. With the research foundation of natural disaster risk theory and drought risk formation principle, we start from dangerousness, exposure, vulnerability and the ability to prevent disaster to filter out 23 indexes range from social status, economy, weather and geology to construct the assessment system of Bijie drought risk. To solve the uncertainty of quantitative description for drought risk assessment index and the judge of assessment result, cloud model and entropy weight method are implemented to decide how much percentage the city or county belong on each index. In the end, we use the weight of 23 indexes to get the drought risk level each city or county belongs to. The result reveal that Weining has the highest risk while Bijie, Qianxi, Zhijin, Hezhang have higher risk of drought occurence and Dafang and Jinsha have normal risk, Nayong has lower risk. This research aims to help governments at all levels to prevent drought and provide decision basis to reduce drought loss.
\end{abstract}

Keywords: Bijie; Drought risk; Normal cloud model; Cloud generator; Entropy weight method;

\section{基于云模型的毕节地区干旱灾害风险评判研究 ${ }^{* *}$}

\author{
贺䓉 \\ 贵州财经大学/金融学院, 贵阳 400020
}

\begin{abstract}
摘要: 本文以贵州省毕节地区的 8 个市、县作为研究对象, 从形成干旱灾害风险的危险性、暴露性、脆弱 性和防灾减灾能力等 4 个因素考虑, 选取气温、降水、日照百分率等方面的 23 个指标, 构建了毕节地区干 旱灾害风险评价指标体系。针对区域干旱灾害风险评价指标定量描述的不确定性和评价结果等级判定的不 确定性, 建立了基于正态云模型和摘权法的区域干旱灾害风险评价模型, 并利用历史数据对毕节地区 8 个 市、县的干旱灾害风险进行了实证测评。结果显示, 威宁县的干旱灾害风险高, 毕节市、黔西县、织金 县、赫章县的干旱灾害风险较高, 大方县、金沙县的干旱灾害风险一般, 纳雍县的干旱灾害风险较低。从 而为各级政府更为有效的指导防灾和备灾, 减少旱灾损失提供了决策依据; 有助于更为有效的对干旱灾害 进行早期预警; 有助于抗旱应急预案的编制。
\end{abstract}

关键词: 毕节地区; 干旱灾害风险; 正态云模型; 云发生器; 熵权法

\section{1. 引言}

由于特殊的地理位置和人均水资源匾乏, 旱灾 成为我国影响范围最广、发生最频繁的气象灾害, 制约了国民经济的可持续发展 ${ }^{[1]}$ 。干旱灾害也是贵 州省毕节地区最主要的自然灾害之一。2009年入秋 以来, 毕节地区发生的四季连旱, 持续时间长、危 害程度深、受灾面积大、经济损失重, 是有气象记

*基金项目：国家自然科学基金项目（71263011）; 教育部人文 社会科学研究规划基金项目（11YJA630196）; 毕节地区 2011 年 科技发展计划项目（[2011]01）
录以来最严重的一次干旱 ${ }^{[2]}$ 。旱灾造成全地区 619.7 万人受灾， 425.24 万人、 139.43 万头牲畜饮水困 难； 585.44 万亩农作物受灾，经济损失达 32.32 亿 元。因此, 通过对毕节地区干旱灾害风险进行综合 评价, 识别干旱高敏感区和高风险区, 可以为各级 政府更为有效的指导防灾和备灾, 减少旱灾损失提 供决策依据; 可以更为有效的对干旱灾害进行早期 预警, 指导各级政府抗旱救灾; 同时, 对当地政府 编制抗旱应急预案, 增强抗旱应急管理能力具有重 要的参考价值 ${ }^{[3]}$ 。

美国国家干旱减灾中心（NDMC）主任 Wilhite 博士将干旱灾害风险定义为: 干旱灾害的出现（即

Published by Atlantis Press

Copyright: the authors 
发生的可能性) 和社会脆弱性的结果 ${ }^{[4]}$ 。综合来 看, 干旱灾害风险可以定义为: 干旱影响范围内暴 露于干旱威胁下的承灾体, 在干旱致灾因子和孕灾 环境的作用下, 由于承灾体自身的脆弱性, 所遭受 损失的可能性及大小。干旱灾害风险是由内部和外 部因素共同导致的, 内部因素是承灾体自身和人类 活动所导致的脆弱性, 外部因素是干旱致灾因子和 孕灾环境的影响。目前, 对于干旱灾害风险评价主 要是运用数学方法, 对干旱灾害的孕灾环境、危险 性和承灾体脆弱性等因素进行综合分析, 最终用干 旱灾害风险度来刻画干旱灾害风险的大小。目前, 评价自然灾害风险的方法可以归纳为如下几种：概 率统计 ${ }^{[5-6]}$ 、模糊数学 ${ }^{[7-9]}$ 、信息扩散理论 ${ }^{[10-11]}$ 、层次 分析法 ${ }^{[12-13]}$ 、灰色系统理论 ${ }^{[14-17]}$ 、人工神经网络 ${ }^{[18-}$ 19]、加权综合评价 ${ }^{[20-21]}$ 等。上述方法各有其优缺 点, 但均未考虑在综合评价中针对干旱灾害风险评 价指标定量描述的不确定性和评价结果等级判定的 不确定性。

针对干旱灾害风险评价指标定量描述的不确定 性和评价结果等级判定的不确定性, 模糊性和随机 性并存, 单纯只考虑模糊性容易造成评价结果的失 真, 有鉴于此, 引入云模型这样一个以自然语言值 为切入点, 实现定性概念与定量数值之间的不确定 性转换的模型; 它把模糊性与随机性这二者完全集 成在一起构成定性和定量相互间的映射它同时反映 了客观世界中概念的两种不确定性, 即随机性(发生 的概率) 和模糊性(亦此亦彼性) ${ }^{[22-24]}$ 。之后, 拟从危 险性、暴露性、脆弱性和防灾减灾能力等四个方面 构建毕节地区干旱灾害风险评价指标体系, 建立了 基于正态云模型和熵权法的区域干旱灾害风险评价 模型, 并利用历史数据对毕节地区 8 个市、县的干 旱灾害风险进行了实证测评。

\section{2. 云模型概述}

云模型是李德毅院士提出的作为不确定性的定 性定量转换的模型, 目的是用于处理定性概念中广 泛存在的随机性和模糊性, 已成功应用于智能控 制、决策分析、图像处理、数据挖掘等领域。云模 型是具有普遍适用性的正态云, 其数字特征用期望 Ex (Expected value), 熵 En (Entropy), 超熵

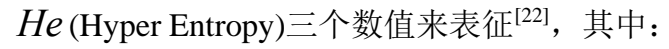

期望 Ex 表示云滴在论域空间分布的期望，是 最能够代表定性概念的点, 或者说是这个概念量化 的最典型样本; 熵 $E n$ 代表定性概念的可度量度, 定性概念的不确定性随着熵越大而变大, 由概念的 随机性和模糊性共同决定。用同一个数字特征来反 映随机性和模糊性, 也必然反映他们之间的关联 性; 超熵 $H e$ 是熵的不确定性度量, 即熵的熵, 由
熵的随机性和模糊性共同决定, 反映了云滴的离散 程度。云模型如图 1 所示:

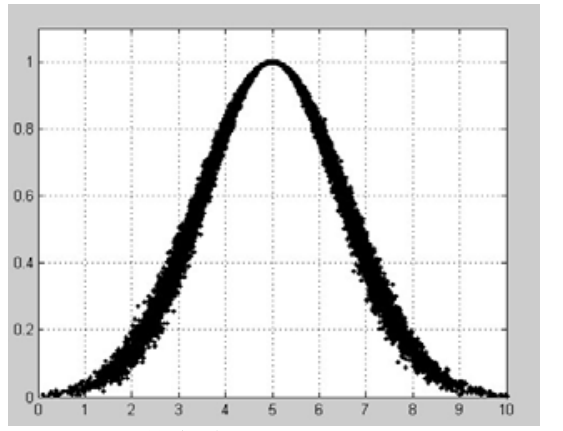

图1 正态云及数字特征 $(\mathrm{Ex}=5, \mathrm{En}=1.5, \mathrm{He}=0.07)$

Fig.1 Normal cloud and digital characteristics $(E x=5, E n=1.5, \mathrm{He}=0.07)$

如果在论域 $U$ 中确定点 $x$, 通过云发生器可以 生成这 $x$ 个特定点属于概念 $C$ 的确定度分布, 这时 的云发生器称为正向云发生器。正向正态云发生器 构建了定性到定量的映射关系, 根据正态云的数字 特征 $(E x, E n, H e)$ 产生云滴, 并确定一个特定点处于 某种概念的确定度分布 ${ }^{[2]}$ 。其具体算法为:

(1) 给定熵 $E n$ 和超熵 $\mathrm{He}$,生成正态分布的随 机数 $E n^{\prime} \sim N\left(E n, H e^{2}\right)$

(2) 利用输入值 $x$ 计算隶属度

$$
\mu(x)=\exp \left[-\frac{(x-E x)^{2}}{2 E n^{\prime 2}}\right]
$$

\section{3. 构建基于正态云模型和熵权的综合评估模型}

根据能客观反映指标权重大小的熵权, 结合定 量到定性的正态云模型, 建立综合评估模型如下 [27]:

步骤 1 , 对于待评估对象建立因素论域

$U=\left\{u_{1}, u_{2}, \ldots, u_{n}\right\}$, 以及定性的评价论域

$V=\left\{v_{1}, v_{2}, \ldots, v_{n}\right\}$;

步骤 2, 用熵权法对指标权重进行计算, 得到 权向量 $W=\left\{w_{1}, w_{2}, \ldots, w_{n}\right\}$ 。具体计算步骤如下所 示。首先, 将第 $i$ 个区县的第 $j$ 个指标的数据 $x_{i j}$ 转 化为该值占第 $j$ 个指标的百分比 $p_{i j}$

$p_{i j}=\frac{x_{i j}}{\sum_{i=1}^{m} x_{i j}}$, 其中 $i=1,2, \ldots, m ; j=1,2, \ldots, n$ 
然后, 定义第 $j$ 个指标的熵为

$H_{j}=-k \sum_{i=1}^{m} p_{i j} \operatorname{Lnp}_{i j}, \quad j=1,2, \ldots, n ; k=\frac{1}{\operatorname{Lnm}}$ (3)

引入常数 $k$ 保证第 $j$ 个指标的 $p_{i j}$ 都相等, 满足 $H_{j}=1$, 此时该指标不能提供任何信息。当 $p_{i j}=0$ 时, 令 $p_{i j} L n p_{i j}=0$, 从而保证 $H_{j} \in[0,1]$ 。最后, 定义第 $j$ 个指标的熵权重为

$$
W=\sum_{j=1}^{n} w_{j}=\frac{1-H_{j}}{\sum_{j=1}^{n}\left(1-H_{j}\right)}=\frac{1-H_{j}}{n-\sum_{j=1}^{n} H_{j}},
$$

步骤 3, 进行单因素评估, 建立模糊关系矩阵 $R$ 。单因素评估即产生从评估对象的因素论域到评 语论域的一对一映射, $R$ 中元素 $r_{i j}$ 表示论域 $U$ 中 第 $i$ 个因素 $u_{i}$ 对应于评语论域 $V$ 中第 $j$ 个等级 $v_{j}$ 的 隶属度, 即一个区县的某一指标 (因素论域) 对于 若干评价等级 (评语论域) 进行映射。设定 $x_{i j}^{1}, x_{i j}^{2}$ 为因素 $i(i=1,2,3, \mathrm{~L}, n)$ 对应评级等级 $j(j=1,2,3, \mathrm{~L}, n)$ 的上、下边界值, 则因素 $i$ 对应 等级 $j$ 这一定性概念可以用正态云模型表示如下

$$
E x_{i j}=\left(x_{i j}^{1}+x_{i j}^{2}\right) / 2
$$

边界值是两个等级的模糊边界, 则此过渡值隶 存在相同概率隶属于两种等级:

$$
\exp \left[-\frac{\left(x_{i j}^{1}-x_{i j}^{2}\right)^{2}}{8\left(E n_{i j}\right)^{2}}\right]=0.5
$$

即

$$
E n_{i j}=\frac{x_{i j}^{1}-x_{i j}^{2}}{2.355}
$$

超熵 $\mathrm{He}_{i j}$ 度量了熵的不确定性, 即云滴的凝聚 程度, 超熵值越小代表云的厚度越小, 反之亦然, 本文根据经验对超熵进行确定 ${ }^{[28]}$ 。

步骤 4 , 利用正向云发生器生成待评价项目的 各个指标对应每个等级的云模型隶属度矩阵

$Z=\left(z_{i j}\right)_{n \times m}$ 。另外, 为提高评估的可信度, 重复运 行 $N$ 次正向云发生器以计算某指标对于某等级的隶 属度的平均值:

$$
z_{i j}=\sum_{k=1}^{N} z_{i j}^{k} / N
$$

步骤 5 , 利用隶属度矩阵 $Z$ 与权重集 $W$ 进行模 糊转换得到评价集上的模糊子集 $B$,

$$
\begin{gathered}
B=Z \bullet W=\left(b_{1}, b_{2}, \ldots, b_{m}\right) \\
b_{j}=\sum_{i=1}^{n} w_{i} z_{i j}, j=1,2, \ldots, m
\end{gathered}
$$

其中 $b_{j}$ 表示待评价对象 (某区县) 对第 $j$ 条评语 (风险等级) 的综合隶属度。根据最大隶属度原 则, 最大隶属度所对应的评价等级 $i$ 即为综合评价 结果。

\section{4. 构建毕节干旱灾害风险综合评价}

\section{1 指标体系和样本数据}

本文以自然灾害风险的形成理论和干旱灾害风 险的形成原理为理论基础, 借鉴自然灾害风险指数 来构建干旱灾害风险评价指标体系。自然灾害风险 指数指未来若干年内可能达到灾害程度及其发生的 可能性, 是危险性、暴露性和脆弱性相互作用的结 果, 而防灾减灾能力由于代表社会对于灾害的认知 和对于自然灾害风险大小也有一定的影响, 即某地 区内的自然灾害风险形成过程是这 4 个因素综合影 响的结果 ${ }^{[29]}$ 。（表 1)。整个指标体系分为准则 层、指标层和子指标指标层, 各指标的权重为熵权 法计算结果 ${ }^{[30]}$ 。

本文所使用的气象指标数据来自毕节市气象局 的统计报告, 水资源指标数据来源于 《毕节地区水 资源公报》（2010），地形指标数据来源于《毕节 地区志--土地志》, 在校学生比例数据来源于《贵州 教育》, 社会经济指标数据来源《毕节地区统计年 鉴 1988-2008》以及《毕节试验区一辉煌十一五》。 指标原始值如表 2 所示。 
表1 干旱灾害风险评价指标体系

Tab.1 The assessment index system of drought risk

\begin{tabular}{|c|c|c|c|c|c|c|c|}
\hline 准则层 & 指标层 & 子指标层 & 权重 & 准则层 & 指标层 & 子指标层 & 权重 \\
\hline \multirow{10}{*}{ 危险性 } & \multirow{3}{*}{ 气象 } & 气温 $U_{1}$ & 0.0187 & 脆弱性 & 人口 & 人均生活用水量 $U_{14}$ & 0.0319 \\
\hline & & 降水 $U_{2}$ & 0.0457 & & & 人均农业用水量 $U_{15}$ & 0.0533 \\
\hline & & 日照百分率 $U_{3}$ & 0.0304 & & & 脆弱性人口比例 $U_{16}$ & 0.0214 \\
\hline & \multirow{4}{*}{ 水资源 } & 土壤湿度 $U_{4}$ & 0.0539 & & & 农村贫困发生率 $U_{17}$ & 0.0184 \\
\hline & & 地下水资源量 $U_{5}$ & 0.0425 & & 经济 & 易旱耕地比率 $U_{18}$ & 0.0204 \\
\hline & & 地表水资源量 $U_{6}$ & 0.0441 & & & 单位 GDP 工业用水量 $U_{19}$ & 0.0521 \\
\hline & & 年末蓄水量 $U_{7}$ & 0.0573 & 防灾能力 & 灌溉能力 & 水田面积 $U_{20}$ & 0.0595 \\
\hline & \multirow{3}{*}{ 地形 } & 耕地坡度 $U_{8}$ & 0.0663 & & 社会经济实力 & 城镇人均可支配收入 $U_{21}$ & 0.0716 \\
\hline & & 水田坡度 $U_{9}$ & 0.0650 & & & 农民人均纯收入 $U_{22}$ & 0.0595 \\
\hline & & 旱地坡度 $U_{10}$ & 0.0448 & & 教育水平 & 在校学生比例 $U_{23}$ & 0.0471 \\
\hline \multirow{3}{*}{ 暴露性 } & 人口 & 人口密度 $U_{11}$ & 0.0235 & & & & \\
\hline & \multirow{2}{*}{ 经济 } & 农林牧渔业产值 $U_{12}$ & 0.0254 & & & & \\
\hline & & 工业总产值 $U_{13}$ & 0.0471 & & & & \\
\hline
\end{tabular}

表2 毕节八个地区指标原始值

Tab.2 The data of 8 counties/cities in Bijie district

\begin{tabular}{ccccccccc}
\hline 指标 & 毕节市 & 大方县 & 黔西县 & 金沙县 & 织金县 & 纳雍县 & 威宁县 & 赫章县 \\
\hline$U_{1}$ & 13.50 & 12.70 & 14.70 & 15.40 & 14.90 & 14.40 & 14.30 & 11.90 \\
$U_{2}$ & 749.70 & 818.80 & 729.40 & 1020.0 & 1195.8 & 995.40 & 796.7 & 815.6 \\
$U_{3}$ & 39.2 & 29.1 & 28.3 & 24.5 & 26.3 & 31.7 & 40.3 & 31.6 \\
$U_{4}$ & 44.40 & 40.00 & 97.20 & 48.00 & 90.40 & 45.00 & 71.20 & 72.20 \\
$U_{5}$ & 4.35 & 4.97 & 4.18 & 3.93 & 6.31 & 4.01 & 8.23 & 5.23 \\
$U_{6}$ & 14.50 & 17.50 & 14.00 & 12.00 & 21.50 & 17.00 & 27.50 & 16.00 \\
$U_{7}$ & 1969.00 & 835.00 & 1268.00 & 1118.00 & 643.00 & 565.00 & 2009.00 & 1200.00 \\
$U_{8}$ & 16.95 & 28.58 & 14.20 & 15.150 & 15.52 & 16.69 & 14.46 & 16.62 \\
$U_{9}$ & 7.54 & 9.86 & 7.06 & 8.12 & 7.86 & 7.93 & 18.80 & 9.93 \\
$U_{10}$ & 17.92 & 18.96 & 15.19 & 16.99 & 16.50 & 17.44 & 14.37 & 16.81 \\
$U_{11}$ & 356.00 & 267.00 & 312.00 & 230.00 & 274.00 & 311.00 & 164.00 & 187.00 \\
$U_{12}$ & 133800.43 & 83710.62 & 100116.67 & 91814.33 & 77922.48 & 64804.10 & 101831.48 & 55552.57 \\
$U_{13}$ & 195450.85 & 50360.57 & 62994.19 & 140309.19 & 53677.48 & 100596.71 & 84175.05 & 77912.24 \\
$U_{14}$ & 29.8200 & 25.1600 & 27.3700 & 28.3300 & 26.1000 & 25.6700 & 31.5900 & 29.9600 \\
$U_{15}$ & 38.8600 & 115.66 & 40.9000 & 99.1300 & 38.46 & 23.01 & 24.8800 & 36.4200 \\
$U_{16}$ & 10.40 & 15.10 & 10.50 & 8.60 & 15.80 & 14.80 & 14.90 & 14.80 \\
$U_{17}$ & 6.90 & 9.9750 & 7.3000 & 4.4750 & 11.00 & 12.5250 & 9.4250 & 10.4750 \\
$U_{18}$ & 0.8923 & 0.8857 & 0.7918 & 0.6909 & 0.7596 & 0.8696 & 0.9867 & 0.9639 \\
$U_{19}$ & 76.8100 & 105.24 & 102.38 & 139.61 & 69.69 & 224.67 & 57.29 & 59.81 \\
$U_{20}$ & 6.8433 & 6.0314 & 9.5495 & 10.9786 & 10.7695 & 4.4024 & 0.9748 & 1.3895 \\
$U_{21}$ & 4064.17 & 3453.50 & 3831.37 & 3455.68 & 3536.21 & 3398.21 & 3628.21 & 3825.16 \\
$U_{22}$ & 1203.13 & 1067.88 & 1164.88 & 1443.5 & 1087.88 & 1101.38 & 961.88 & 1083.75 \\
$U_{23}$ & 0.1963 & 0.2064 & 0.2136 & 0.2022 & 0.1995 & 0.1856 & 0.1422 & 0.1580 \\
\hline & & & & & & & & \\
\hline
\end{tabular}




\section{2 干旱灾害风险评价等级划分}

对于 23 个指标, 为使得在云模型中隶属度的计 算更为准确, 需要对每个指标的数值进行区划, 构 建针对风险等级的低、较低、一般、较高、高五个 数值范围。由于影响干旱的因素很多, 造成干旱的
原因不同, 各地气候、地理条件差异很大, 目前难 以采用全国统一的干旱评判标准。因此在参考若干 文献基础上, 结合气象学、地质学、社会学等学科 知识分析各个指标与干早之间的联系, 进行干旱灾 害风险评价等级的划分 ${ }^{[31-33]}$, 如表 3 所示。

表3 干旱灾害风险评价等级划分

Tab.3 Level grading of drought risk assessment

\begin{tabular}{|c|c|c|c|c|c|c|c|c|c|c|c|}
\hline 指标 & 低风险 & 较低风险 & 一般风险 & 较高风险 & 高风险 & 指标 & 低风险 & 较低风险 & 一般风险 & 较高风险 & 高风险 \\
\hline$U_{1}$ & $0-10$ & $10-12$ & $12-14$ & $14-16$ & $16-20$ & $U_{13}$ & $0-50000$ & $\begin{array}{c}50000- \\
90000\end{array}$ & $\begin{array}{c}90000- \\
130000\end{array}$ & $\begin{array}{c}130000- \\
170000\end{array}$ & $\begin{array}{l}170000 \\
220000\end{array}$ \\
\hline$U_{2}$ & $1100-1400$ & $900-1100$ & $650-900$ & $500-650$ & $0-500$ & $U_{14}$ & $0-20$ & $20-24$ & $24-28$ & 28-31 & $31-38$ \\
\hline$U_{3}$ & $0-14$ & $14-22$ & $22-30$ & $30-38$ & $38-50$ & $U_{15}$ & $0-30$ & $30-55$ & $55-80$ & 80-100 & $100-130$ \\
\hline$U_{4}$ & 91-105 & $77-91$ & $63-77$ & $44-63$ & $0-44$ & $U_{16}$ & $0-5$ & $5-8$ & 8-11 & $11-15$ & $15-20$ \\
\hline$U_{5}$ & $7.5-9$ & $6.5-7.5$ & $5.5-6.5$ & $3.5-5.5$ & $0-3.5$ & $U_{17}$ & $0-4$ & $4-6$ & $6-9$ & $9-12$ & $12-16$ \\
\hline$U_{6}$ & $26-34$ & $22-26$ & $17-22$ & $12-17$ & $0-12$ & $U_{18}$ & $0-0.4$ & $0.4-0.6$ & $0.6-0.8$ & $0.8-1$ & $1-1.3$ \\
\hline$U_{7}$ & $1900-2300$ & $1400-1900$ & $900-1400$ & $500-900$ & $0-500$ & $U_{19}$ & $0-60$ & 60-105 & $105-155$ & $155-205$ & $205-250$ \\
\hline$U_{8}$ & $0-15$ & $15-19$ & $19-22$ & $22-26$ & $26-32$ & $U_{20}$ & $10.5-14$ & 8-10.5 & $5.5-8$ & $2.5-5.5$ & $0-2.5$ \\
\hline$U_{9}$ & $0-8$ & $8-10$ & $10-14$ & $14-18$ & $18-24$ & $U_{21}$ & $4000-4500$ & $3650-4000$ & $3300-3650$ & $3000-3300$ & $0-3000$ \\
\hline$U_{10}$ & $0-7$ & $7-11$ & $11-15$ & $15-19$ & $19-23$ & $U_{22}$ & $1500-2000$ & $1250-1500$ & $1000-1250$ & $800-1000$ & $0-800$ \\
\hline$U_{11}$ & $0-130$ & $130-200$ & $200-270$ & $270-330$ & $330-400$ & $U_{23}$ & $0.21-0.3$ & $0.19-0.21$ & $0.17-0.19$ & $0.15-0.17$ & $0-0.15$ \\
\hline$U_{12}$ & $0-50000$ & $\begin{array}{l}50000- \\
80000\end{array}$ & $\begin{array}{l}80000- \\
100000\end{array}$ & $\begin{array}{c}100000- \\
120000\end{array}$ & $\begin{array}{c}120000- \\
160000\end{array}$ & & & & & & \\
\hline
\end{tabular}

\section{3 毕节地区各区县干旱灾害风险计算}

本文通过对搜集的数据进行整理, 并根据公式 (5)、公式(7)计算出期望、熵, 结合干旱灾害风险评 价指标体系和评价等级划分, 将五个等级的正态云 模型（包含期望、熵、超熵）表示如表 4, 其中超 熵根据经验选定。

例如, 将日照百分率这一指标利用公式(1)和云 矩阵 $R$ 中 $U_{3}$ (如表 4)的数值, 建立五个风险等级的正 态云隶属度函数, 遵循清晰化原则来确定日照百分 率的超熵, 如图 2 所示。

假定步骤 4 反复计算次数 $N=200$ ，例如，将 毕节市干旱灾害风险量化数据代入上述正向正态云 发生器, 重复计算 200 次, 计算在不同隶属度情况 下的平均综合评估值, 即得出毕节市各个指标对于 不同风险等级的隶属情况如表 5 所示。

最终, 根据步骤 5 利用各指标权重与隶属度矩 阵 $Z$ 进行模糊转换得出评价集 $V$ 上的模糊子集 $B$ 。 依据最大隶属度原则, 选择最大的隶属度所对应的 第 $i$ 个评价等级作为综合评价的结果。根据收集到
的所有县市指标数据, 同理可得计算出毕节地区 8 个县、市的干旱灾害风险等级隶属度, 如表 6 所 示。

根据计算结果可知, 由于毕节地区乃至贵州省 都是经济水平、教育水平以及地理环境较差的地 域, 所以没有任何市县干旱风险低, 威宁县的干旱 灾害风险高, 毕节市、黔西县、织金县、赫章县的 干旱灾害风险较高, 大方县、金沙县的干旱灾害风 险一般, 纳雍县的干旱灾害风险较低。

\section{4 云模型与模糊综合评价法差异比较}

为验证云模型评价的有效性, 引入模糊综合评 价法进行评价结果对比。模糊综合评价一般采取专 家评审打分的方法建立模糊关系矩阵, 本文试图根 据指标的等级划分数据, 为指标建立单因素与隶属 度的映射关系: 设某一个指标的某一等级的上下限 为 $x_{i j}^{1}, x_{i j}^{2}$, 设定如下函数式(10), 并将原始值带入各 个隶属度函数进行运算得出表 7 结果。 
Ying He

表4 干旱灾害风险正态云标准值

Tab.4 The normal cloud standard value on drought risk

\begin{tabular}{|c|c|c|c|c|c|}
\hline 指标 & 低风险 & 较低风险 & 一般风险 & 较高风险 & 高风险 \\
\hline$U_{1}$ & $(18,1.7,0.1)$ & $(15,0.85,0.1)$ & $(13,0.85,0.1)$ & $(11,0.85,0.1)$ & $(5,4.25,0.1)$ \\
\hline$U_{2}$ & $(250,212.31,7)$ & $(575,63.69,7)$ & $(775,106.16,7)$ & $(1000,84.93,7)$ & $(1250,127.39,7)$ \\
\hline$U_{3}$ & $(44,5.1,0.1)$ & $(34,3.4,0.1)$ & $(26,3.4,0.1)$ & $(18,3.4,0.1)$ & $(7,5.94,0.1)$ \\
\hline$U_{4}$ & $(22,18.68,0.3)$ & $(53.5,8.07,0.3)$ & $(70,5.94,0.3)$ & $(84,5.94,0.3)$ & $(98,5.94,0.3)$ \\
\hline$U_{5}$ & $(1.75,1.49,0.05)$ & $(4.5,0.85,0.05)$ & $(6,0.42,0.05)$ & $(7,0.42,0.05)$ & $(8.25,0.64,0.05)$ \\
\hline$U_{6}$ & $(6,5.1,0.1)$ & $(14.5,2.12,0.1)$ & $(19.5,2.12,0.1)$ & $(24,1.7,0.1)$ & $(30,3.4,0.1)$ \\
\hline$U_{7}$ & $(250,212.31,8)$ & $(700,169.85,8)$ & $(1150,212.31,8)$ & $(1650,212.31,8)$ & $(2100,169.85,8)$ \\
\hline$U_{8}$ & $(29,2.55,0.1)$ & $(24,1.7,0.1)$ & $(20.5,1.27,0.1)$ & $(17,1.7,0.1)$ & $(7.5,6.37,0.1)$ \\
\hline$U_{9}$ & $(21,2.55,0.1)$ & $(16,1.7,0.1)$ & $(12,1.7,0.1)$ & $(9,0.85,0.1)$ & $(4,3.4,0.1)$ \\
\hline$U_{10}$ & $(21,1.7,0.04)$ & $(17,1.7,0.04)$ & $(13,1.7,0.04)$ & $(9,1.7,0.04)$ & $(3.5,2.97,0.04)$ \\
\hline$U_{11}$ & $(365,29.72,2)$ & $(300,25.48,2)$ & $(235,29.72,2)$ & $(165,29.72,2)$ & $(65,55.2,2)$ \\
\hline$U_{12}$ & $(140000,16985.14,1500)$ & $(110000,8492.57,1500)$ & $(90000,8492.57,1500)$ & $(65000,12738.85,1500)$ & $(25000,21231.42,1500)$ \\
\hline$U_{13}$ & $(195000,21231.42,1500)$ & $(150000,16985.14,1500)$ & $(110000,16985.14,1500)$ & $(70000,16985.14,1500)$ & $(25000,21231.42,1500)$ \\
\hline$U_{14}$ & $(34.5,2.97,0.05)$ & $(29.5,1.27,0.05)$ & $(26,1.7,0.05)$ & $(22,1.7,0.05)$ & $(10,8.49,0.05)$ \\
\hline$U_{15}$ & $(115,12.74,0.8)$ & $(90,8.49,0.8)$ & $(67.5,10.62,0.8)$ & $(42.5,10.62,0.8)$ & $(15,12.74,0.8)$ \\
\hline$U_{16}$ & $(17.5,2.12,0.1)$ & $(13,1.7,0.1)$ & $(9.5,1.27,0.1)$ & $(6.5,1.27,0.1)$ & $(2.5,2.12,0.1)$ \\
\hline$U_{17}$ & $(14,1.7,0.08)$ & $(10.5,1.27,0.08)$ & $(7.5,1.27,0.08)$ & $(5,0.85,0.08)$ & $(2,1.7,0.08)$ \\
\hline$U_{18}$ & $(1.15,0.13,0.005)$ & $(0.9,0.08,0.005)$ & $(0.7,0.08,0.005)$ & $(0.5,0.08,0.005)$ & $(0.2,0.17,0.005)$ \\
\hline$U_{19}$ & $(227.5,19.11,1)$ & $(180,21.23,1)$ & $(130,21.23,1)$ & $(82.5,19.11,1)$ & $(30,25.48,1)$ \\
\hline$U_{20}$ & $(1.25,1.06,0.1)$ & $(4,1.27,0.1)$ & $(6.75,1.06,0.1)$ & $(9.25,1.06,0.1)$ & $(12.25,1.49,0.1)$ \\
\hline$U_{21}$ & $(1500,1273.89,8)$ & $(3150,127.39,8)$ & $(3475,148.62,8)$ & $(3825,148.62,8)$ & $(4250,212.31,8)$ \\
\hline$U_{22}$ & $(400,339.7,5)$ & $(900,84.93,5)$ & $(1125,106.16,5)$ & $(1375,106.16,5)$ & $(1750,212.31,5)$ \\
\hline$U_{23}$ & $(0.075,0.06,0.007)$ & $(0.16,0.01,0.007)$ & $(0.18,0.01,0.007)$ & $(0.2,0.01,0.007)$ & $(0.255,0.04,0.007)$ \\
\hline
\end{tabular}

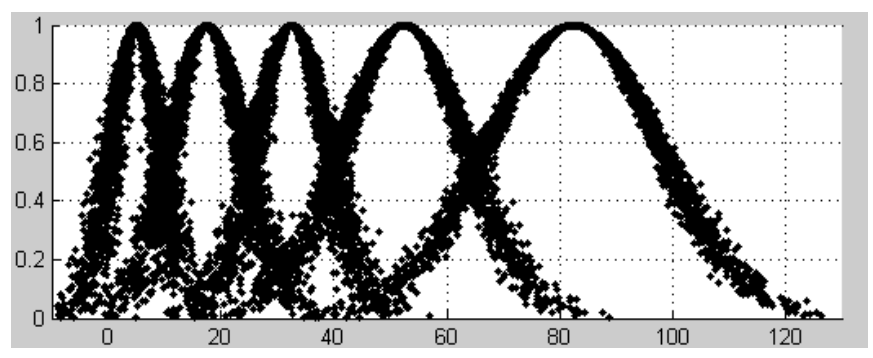

图2 正态云隶属度

Fig.2 The normal cloud membership 
表6 毕节地区8个县、市干旱灾害风险隶属度结果

Tab.6 The evaluation result of drought risk level for 8 counties/cites

\begin{tabular}{ccccccc}
\hline 县、市 & 低 & 较低 & 一般 & 较高 & 高 & 最终等级 \\
\hline 毕节市 & 0.2 & 0.24 & 0.22 & 0.28 & 0.19 & 较高 \\
大方县 & 0.24 & 0.23 & 0.42 & 0.14 & 0.07 & 一般 \\
黔西县 & 0.06 & 0.19 & 0.31 & 0.32 & 0.21 & 较高 \\
金沙县 & 0.13 & 0.27 & 0.33 & 0.26 & 0.16 & 一般 \\
织金县 & 0.07 & 0.17 & 0.31 & 0.35 & 0.24 & 较高 \\
纳雍县 & 0.19 & 0.35 & 0.28 & 0.21 & 0.13 & 较低 \\
威宁县 & 0.23 & 0.17 & 0.23 & 0.17 & 0.24 & 高 \\
赫章县 & 0.14 & 0.27 & 0.3 & 0.35 & 0.11 & 较高 \\
\hline
\end{tabular}

表5 毕节市云模型平均综合评估值

Tab.5 The average comprehensive evaluation value of cloud model for Bijie city

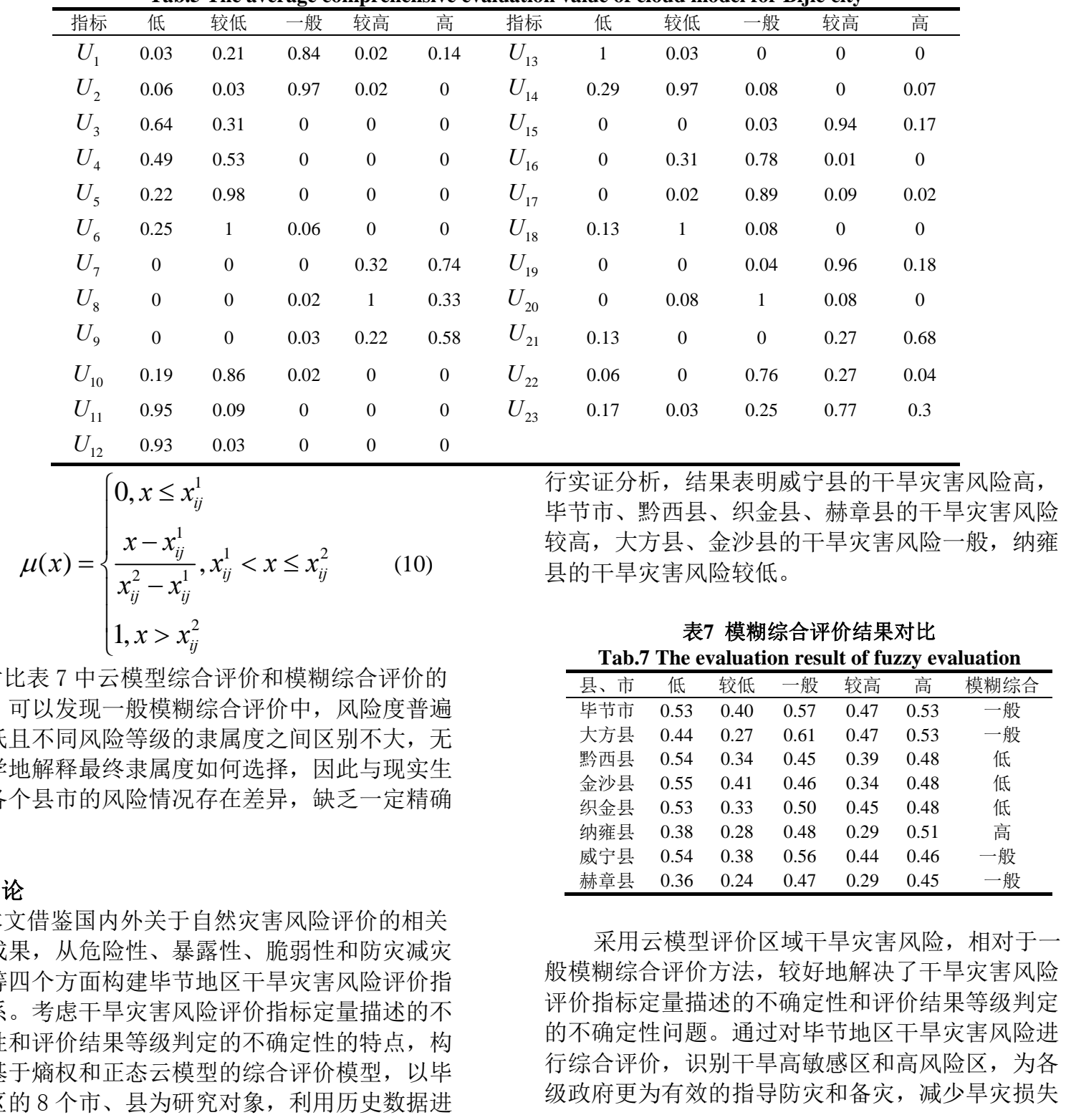


提供了决策依据; 有助于更为有效的对干早灾害进 行早期预警，指导各级政府抗旱救灾; 同时, 对当 地政府编制抗旱应急预案, 增强抗旱应急管理能力 具有重要的参考价值。

\section{参考文献}

1. C.Jiawi, W.Hao. Survey of Water Resource[M].Beijing, China water conservancy and Hydropower Press, 1996:14-15 陈家琦,王浩. 水资源学概论 [M]. 北京: 中国水利水电出 版社, 1996:14-15.

2. Shang Chongju, Wang Qun, Hao Zhibin. From 2009 to 2010 in Guizhou province drought disaster cause, characteristics and influence of [J]. Chinese water resources, 2010 (17): 11-13

商崇菊,王群,郝志斌. 贵州省 2009-2010 年特大干旱 灾害成因、特点及影响浅析[J]. 中国水利, 2010(17): 11-13.

3. Chen Jizu 3. Henan province regional drought risk assessment [D]. Zhengzhou: Zhengzhou University, 2010 陈继祖. 河南省区域干旱灾害风险评估[D]. 郑州: 郑州 大学, 2010.

4. Wilhite D A. Drought as a natural hazard: Concepts and definitions[C]. Wilhite D A. Drought: A Global Assessment[M]. London \& New York: Routledge, 2000, 3-18.

5. Ma Yinsheng, Zhang Yecheng, Zhang Chunshan, Wang Jinshan. Theory and method of risk assessment of geological hazards [J]. Journal of geological mechanics, 2004, 10 (1): 7-18

马寅生,张业成,张春山,王金山.地质灾害风险评价的理 论与方法[J].地质力学学报, 2004, 10(1): 7-18.

6. Korkmaz K A. Earthquake disaster risk assessment and evaluation for Turkey[J]. Environmental Geology, 2009, 57(2): 307-320.

7. Chen K, Blong R, Jacobson C. MCE-RISK: integrating multicriteria evaluation and GIS for risk decision-making in natural hazards[J]. Environmental Modelling \& Software, 2001, 16(4) : 387-397.

8. Hsu C, Hong Z. An Intelligent Typhoon Damage Prediction System from Aerial Photographs[J]. SpringerVerlag Berlin Heidelberg, 2007, 747-756.

9. Cao Yongqiang, Li Xiangyun, Ma Jing, Iggy beauty. Assessment of agricultural drought risk Dalian variable fuzzy algorithm based on [J]. resources science, 2011,33 (5).983-988

曹永强,李香云,马静,伊吉美. 基于可变模糊算法的大连 市农业干旱风险评价[J].资源科学, 2011,33(5): 983-988.

10. Feng L, Luo G. Flood Risk Analysis Based on Information Diffusion Theory[J]. Human and Ecological Risk Assessment,2008,14(6):1330-1337.
11. Huang C. Integration degree of risk in terms of scene and application[J]. Stochastic Environmental Research and Risk Assessment,2009, 23(4): 473-484.

12. Zhang Jiquan, Liu Xingpeng, Tong Zhijun. The grassland fire disaster risk assessment and regionalization of [J]. geographical research, 2007, 26 (4): 755-762 张继权,刘兴朋, 佟志军. 草原火灾风险评价与分区[J]. 地 理研究, 2007, 26(4): 755-762.

13. Castellanos Abella E A, Van Westen C J. Generation of a landslide risk index map for Cuba using spatial multicriteria evaluation[J]. Landslide, 2007, 4(4):311-325.

14. Liu Hexiang, Xu Qingjuan. Regional flood disaster risk fuzzy comprehensive evaluation and prediction of [J]. disaster science, 2007,22 (4): 38-42

刘合香,徐庆娟. 区域洪涝灾害风险的模糊综合评价与 预测[J].灾害学, 2007, 22(4): 38-42.

15. Xinhu Mao, Liu Zhankui, Li Xiuqing. Application of [J]. Journal of Southwest University for Nationalities in the mine geology disaster risk zoning evaluation of grey clustering method: Natural Science Edition, 2008,34 (3): 545-551

毛新虎,刘占鬼, 李秀青. 灰色聚类法在矿山地质灾害危 险性分区评价中的应用[J].西南民族大学学报:自然科 学版, 2008, 34(3): 545-551.

16. Chen Nanxiang, Li Shihui, Yang Li. Grey fuzzy clustering theory application in the arid evaluation [J]. North China Institute of water conservancy and hydroelectric power, 2007, 28 (2): 4-7

陈南祥, 李士辉, 杨莉. 灰色模糊聚类理论在干旱评价中 的应用[J].华北水利水电学院学报, 2007, 28(2):4-7.

17. Ma Jianqin, Wei Rui. Fuzzy comprehensive evaluation of the agricultural drought evaluation index system and its application [J]. Anhui agricultural science, based on the 2010, 38 (19): 10138-10140

马建琴, 魏芯. 基于模糊综合评判的华北地区农业干旱 评价指标体系及其应用[J]. 安徽农业科学, 2010, 38, (19): 10138-10140.

18. Aleotti P, Chowdhury R. Landslide hazard assessment: summary review and new perspectives[J]. Bulletin of Engineering Geology and the environment, 1999, 58(1): 21-44.

19. Chen K, Blong R, Jacobson C. Towards an Integrated Approach to Natural Hazards Risk Assessment Using GIS :With Reference to Bushfires[J].Environmental Management,2003,31(4):546-560.

20. Mansor S, Shariah M A, Billa L, et al. Spatial technology for natural risk management[J]. Disaster Prevention and Management, 2004, 13 (5):364-373.

21. Raaijmakers R, Krywkow J, Veen A. Flood risk perceptions and spatial multi-criteria analysis: an exploratory research for hazard mitigation[J].Natural Hazards,2008,46(3):307-322.

22. Li Deyi, Liu Changyu. On the normal cloud model of the universal [J]. China Engineering Science,.2004,6 (8): 2834 
李德毅,刘常昱. 论正态云模型的普适性[J]. 中国工程科 学.2004,6(8):28-34.

23. Li Deyi. Knowledge representation in KDD based on linguistic atoms $[\mathrm{J}]$. Journal of Computer Science and Technology, 1997,12(6):481—496.

24. Li Deyi, Du Yi. Uncertainty in artificial intelligence [M]. Beijing: National Defence Industry Press, 2005.34-56 李德毅,杜貖鸟.不确定性人工智能 [M]. 北京:国防工业出 版社,2005.34-56.

25. Xie Chi, Zhong Zan. Entropy method in comprehensive evaluation of bank performance in the [J]. Chinese soft science,.2002 (9): 108-110

谢赤, 钟赞.熵权法在银行经营绩效综合评价中的应用 [J].中国软科学,.2002 (9):108-110.

26. Tang Yungang. Entropy method of real estate listing Corporation financial performance evaluation research of real estate on [J]..2012,10:53-58

汤云刚. 摘权法下房地产上市公司财务绩效评价研究 [J].房地产开发.2012,10:53-58.

27. Gong Yanbing, Zhang Jiguo. Comprehensive evaluation of population modernization development of the normal cloud model and entropy [J]. China population resources and environment based on.2012,1:138-143

龚艳冰, 张继国. 基于正态云模型和熵权的人口发展现 代化程度综合评价 [J]. 中国人口资源与环 境.2012,1:138-143.

28. Gong Yanbing 28. Normal cloud model and entropy weight comprehensive evaluation of ecological risk city in Hexi Corridor [J]. Journal of arid land resources and environment based on, 2012, 5: 169-174

龚艳冰. 基于正态云模型和熵权的河西走廊城市化生 态风险综合评价[J].干旱区资源与环境，2012，5：169174.

29. Zhao Jing, Zhang Jiquan, Yan Denghua et al..2012,1:5558. GIS in the north area of Henan Province drought disaster risk zoning of disaster based on [J] 赵静,张继权,严登华等. 基于 GIS 的豫北地区干旱灾害 风险区划[J].灾害学, 2012,1:55-58.

30. Yang Chunyan, Wang Jingai, Su Jun, Wang Zhiqiang. Assessment of agricultural drought vulnerability in the northern ecotone Xinghe County as an example [J]. Journal of natural disasters, 2005,14 (6): 89-93

杨春燕, 王静爱, 苏笏, 王志强. 农业旱灾脆弱性评价-以 北方农牧交错带兴和县为例 [J].自然灾害学报, 2005, 14(6): 89-93.

31. Huang Chongfu, Liu Xinli, Zhou Guoxian et al. To the historic disaster data of agricultural natural disaster risk assessment method according [J]. Journal of natural disasters, 1998,7 (2): 1-9

黄崇福, 刘新立, 周国贤等. 以历史灾情资料为依据的农 业自然灾害风险评估方法 [J]. 自然灾害学 报, 1998,7(2):1-9.

32. Ye Jin, Lin Guangfa, Zhang Mingfeng. Research progress of [J]. 2010,9:20-25. Journal of Institute of Disaster Prevention natural disaster risk assessment
叶金玉, 林广发, 张明锋. 自然灾害风险评估研究进展 [J]. 防灾科技学院学报, 2010, 9: 20-25.

33. Zhang Jiquan, Liang Jingdan, Zhou Daowei. GIS based risk assessment of ecological disasters in Jilin province [J] Chinese Journal of Applied Ecology 2007,8:1765-1770 张继权,梁警丹, 周道玮. 基于 GIS 技术的吉林省生态灾 害风险评价[J]. 应用生态学报, 2007,8:1765-1770. 